\title{
Using Synergies between User Stories in Scrum
}

\author{
F. Sobiech, B. Eilermann, and A. Rausch
}

\begin{abstract}
Multi-Requestor-IT-Systems have special needs regarding the requirements engineering and development process. In combination with Scrum, as a software development process, the management of User Stories is especially difficult for the Product Owner because there is no specific "customer". Different requestors envision different requirements of the system. This results in deviating demands with varying priorities for these demands and the subsequently derived User Stories. Nevertheless different User Stories from different requestor's have the ability to save resources if they were combined during the requirements specification and the later development. Therefore, we present a method for systematically using these opportunities in Scrum by adding Product Owner Stories as a new type of Backlog elements.
\end{abstract}

Index Terms-Scalable agile, scrum, user stories, product owner stories.

\section{INTRODUCTION}

Presently, the automotive sector finds itself in a rapid and continual changing process. The competition in the automotive sector requires a continuous improvement process of the products as well as for the processes. That implies for the IT to improve the quality of software systems and to reduce costs for the development, maintenance and operation in order to create competitive advantages. Therefore there is a requirement for consolidation and standardization [1].

Software systems in the automotive industry, such like management information systems, are, in comparison, different to software systems, which are supported and financed by a real market. This is due to the fact that the systems in the automotive industry are, for example, supported and financed by different organizational units within a company. Due to this factor, the IT not only has to fulfil the different expectations of the requestors but also respect the strategic decisions and goals of management. Although this observation is made in the automotive industry, it is not only specific for it, but can be generalized to other in-house software development projects in large companies.

In order to fulfil these expectations and to be able to react faster on changing or new requirements and arising technology trends, agile processes like Scrum are getting more attention in the industrial context [2].

In combination with Scrum as an agile software development framework for managing software projects, the role of the Product Owner is of particular importance for the

Manuscript received October 6, 2014; revised December 23, 2014

F. Sobiech and A. Rausch are with the Clausthal University of Technology, Clausthal, Germany (e-mail: fabian.sobiech@volkswagen.de, andreas.rausch@tu-clausthal.de).

B. Eilermann is with the Technical University of Berlin, Berlin, Germany (e-mail: beate.eilermann@volkswagen.de). whole process, because the Product Owner is representative of the requestors. He is in charge of the prioritization, the maximization for the added value at the end of an iteration [3] as well as he serves as the contact person for the different requestors. Furthermore he fulfils the role of the "on-site-customer". Therefore he is the first person, which is asked by the different development teams for clarification and specifications of the different User Stories [4].

In combination with multiple requestors and multiple development teams the need of coordination grows, leading to a Product Owner overload [5]. But in such environments the Product Owner should be able to analyze the different US in order to find partial coverings and synergies, which can be used for resource savings in development.

Therefore our research questions are: How can we use synergies between different User Stories from different requestors in Scrum?

In order to enable the Product Owner to analyze and find synergies within the different requirements from the different requestors, other tasks of the Product Owner have to be simplified or outsourced to other roles or persons. One approach is to implement the role of "Story Owners". Story Owners are responsible for a dedicated set of User Stories and the communication about these requirements with the different development teams. According to Daut this variation of Scrum allows a better scalability and leads to a workload reduction for the Product Owner [5]. Another possibility to reduce the workload of the Product Owner is to ease the task of User Story prioritization, which will be discussed in the second part of this paper. The third part of this paper briefly presents the idea of Product Owner Stories, their relevance and their usage. The fourth part describes the implications for the value definition and presents an approach to calculate the value for a set of Product Owner Stories, before concluding this paper.

\section{SimPLIFYING THE PRIORITIZATION OF USER STORIES WITH MULTIPLE REQUESTORS}

The basic idea to relieve the role of the Product Owner is to shift the task of the prioritization partly from the Product Owner to the multiple requestors.

In order to shift this task, the needed information by the requestors have to be identified. Due to several interviews with different requestors within the automotive industry we identified several information needs. Besides a description of the requirement and its effect to the software system, the costs for the development and additional costs for the service or maintenance are important in order to take a well-informed prioritization decision. Another information need is the value.

The description of requirements in Scrum is done with User Stories. Each User Story contains a short description of the 
requirement as well as an effort estimation in story points. By knowing the team's capacity for the next iteration we are able to estimate the implementation costs.

The value estimation for User Stories is more complicated since it is done by the Product Owner implicitly without a formalization, but with experience. Also the literature does not describe a universal solution on estimating the value of User Stories [6]. In order to generate the needed information about the estimated value we identified several valuedimensions. The identification of the value dimensions is based on an earlier systematic literature analyse [7]. Based on this literature analysis and the questioning of active stakeholders we identified seven possible value-dimensions (cf. Table I).

Afterwards we asked active requestors, stakeholders and Product Owners $(N=21)$ of an international car manufacturer if these identified value dimensions would be relevant for their prioritization decision. Table I shows the results of this case study.

TABLE I: IDENTIFIED VALUE DIMENSIONS

\begin{tabular}{ll}
\hline \multicolumn{1}{c}{ value-dimension } & acceptance in [\%] \\
\hline financial value & 100.00 \\
\hline work organizational value & 100.00 \\
\hline negative value (if not implemented) & 90.48 \\
\hline software qualitative value & 85.71 \\
\hline intangible value & 61.90 \\
\hline strategic value (requestor) & 57.14 \\
\hline strategic value (IT) & 14.29 \\
\hline
\end{tabular}

Due to the identification of these different value-dimensions it is possible to estimate the value of a User Story and to add this value estimation to a User Story. Analogue to the effort estimation the different requestors shall estimate the value for the different value dimensions and add them to the User Story. This enables other requestors to take these information and embed them into their prioritization decision.

In a next step it is necessary to find a method that aggregates the different prioritizations decisions from the different requestors to a global prioritization in the Product Backlog. Possible methods for this aggregation of the different prioritization decisions are, for example, cumulative voting or the usage of the analytic hierarchy process (AHP) [8].

\section{SYNERGIES BETWEEN USER STORIES IN SCRUM}

As mentioned in the introduction the goal of this research is to identify synergies between different User Stories from different requestors and use them, for example, for cost savings in the development. The usage of synergies should not lead to a higher liability of the requestors. Also the amount of communication should not exceed the current amount of communication, because a need for more communication and coordination might slow down the agile development process.

In order to reach the goal to use synergies between different User Stories for resource savings in the development we want to add another product backlog element into the hierarchy of Epics, User Stories and tasks.
We call this element Product Owner Story, since User Stories express a requirement from the point of view of an user or requestor. Product Owner Stories are maintained by the Product Owner and they express an optimized combination and consolidation of User Stories from the view of the Product Owner.

Product Owner Stories differ from classical Scrum and classical User Stories. They do not belong to an explicit stakeholder or requestor, but to one or multiple User Stories of different requestors. The usage of Product Owner Stories enables the Product Owner to express synergies between User Stories from different requestors. Since Product Owner Stories are created and maintained by the Product Owner they are at least partially hidden from the requestors. Fig. 1 visualizes the usage of Product Owner Stories and their integration into the classical Scrum hierarchy of Epics, User Stories and Tasks [9].

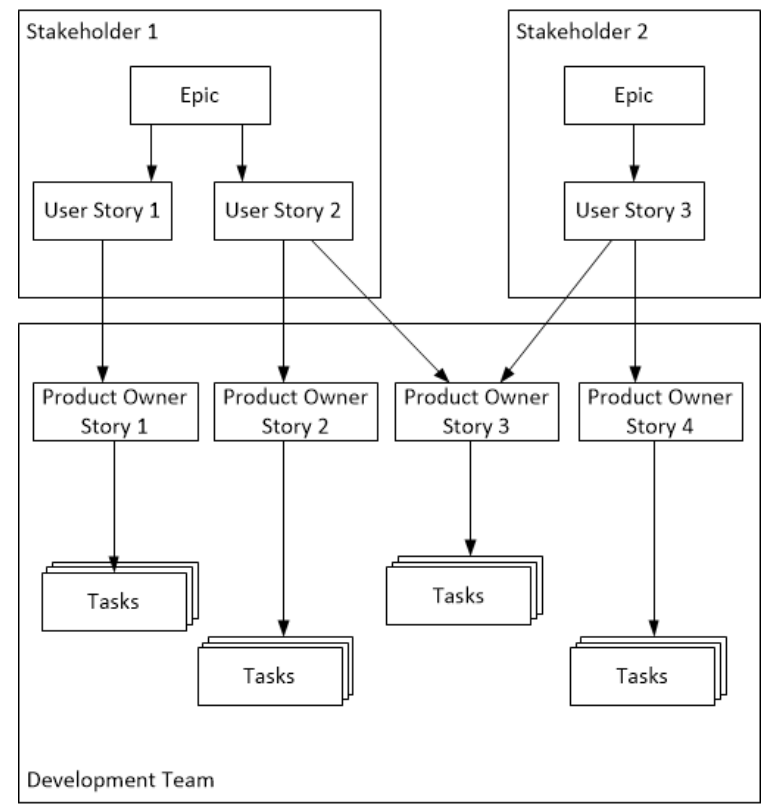

Fig. 1. Visualisation of the usage of POS.

The advantage is that requestors are not involved in this process and don't have to invest more time into development process. Although, continuous involvement of requestors is mandatory for the agile development process, but the involvement is sometimes conflicting with other tasks of the requestors within a company. Since the Product Owner is in charge of the identification of synergies between User Stories and the creation of Product Owner Stories his workload is increased. To avoid a Product Owner overload we shifted the prioritization of User Stories from the Product Owner over to the requestors.

The basic assumption behind the his idea is that if a development team implements parts of different User Stories as one package, the time for the development might be lowered and due to this coast savings can be achieved. Another benefit is that a combined implementation leads to a better and more consistent software architecture.

As an example think of a management information system with two different requiremts from two different requestors. Their aim is to get certain report each but the data that is needed for their different reports is stored in the same data warehouse. As consequence the task for the development 
team of the management information system is to implement a interface to the data warehouse in order to get the needed data. If these two User Stories are not be bundled and treated independently, it could possibly happen that a new interface to collect the data is implemented, just satisfying the information needs for one of these User Stories. In such a case the effort for the implementation growth because you have to set up a second interface or change the first interface after its implementation. In order to avoid such situations e.g. common interfaces between two or more User Stories can be bundled within one Product Owner Story. Aufter the Product Owner Story is implemented we only have one interface that satisfies all needs of all User Stories. So we avoid possible double implementations or changes within the software. This usually leads to a better software architecture and to cost savings within the development process.

\section{VAlue Estimation with PRoduct OWNer Stories}

With the new element between User Stories and Tasks there is no direct linkage between tasks and the value which belongs to a User Story. This is because a User Story is not neccisarily represented by exactly one Product Owner Story but by a set of Product Owner Stories. Therefore the value of a certain sprint backlog with several Product Owner Stories is not directly calculatabel.

Fig. 1 shows a hypothetical of three user Stories and a decomposition into four Product Owner Stories. If, for example, a sprint backlog consists of Product Owner Story 2 and Product Owner Story 4 out of the examaple, the achieved value after their implementation would be zero. This is because neither User Story 2 nor User Story 3 is completely implemented. So in the worst-case scenario no shippable product increment is created or no new usable function from the perspective of the stakeholders is available in this increment.

In order to solve this problem we defined the value not for exactly one Product Owner Story but for a set of Product Owner Stories. So let $\mathrm{U}$ be a set of User Stories and let $\mathrm{P}$ be a set of Product Owner Stories. Further we define a set $M$ of subsets of $\mathrm{P}$, which contains for every $u \in \mathrm{U}$ a set $\mathrm{M}_{u}$ that contains all $p \in \mathrm{P}$ that have to be implemented to fulfil the User Story $u$. So as an example $\mathrm{M}_{\mathrm{User} \mathrm{Story} 2}=\{$ 'Product Owner Story 2', 'Product Owner Story 3'\} (see Fig. 1).

These three sets model the relation betwenn the User Stories and the Product Owner Stories which is in case the imaginery line where the responsibilty swaps over from the Stakeholder to the Development Team. As a result of this set theoretical definition we are able to define the value of a set $\mathrm{P}^{*} \subseteq \mathrm{P}$ as $\sum_{u \in v} v(u) \times x$ with $x(u)=1$ if $\mathrm{M}_{u} \subseteq \mathrm{P}^{*}$ and 0 otherwise and $v(u)$ returns the value of the User Story. With this formulation we define the value of a set of Product Owner Stores by the sum of the values of completely implemented User Stories.

\section{CONClusion ANd Future AgEndA}

In this paper we presented the idea of Product Owner
Stories as a new Product Backlog element to enable the Product Owner to handle synergies between different User Stories from different requestors in order to reduce the number of necessary changes. This leads to time and cost savings during the implementation because double implementations will be eliminated and time consuming changes will be evaded.

Afterwards we defined the concept of value for Product Owner Stories. Since we have many to many relation between User Stories and Product Owner Stories a direct calculation of the value of Product Owner Story is not always possible, we defined the concept of value for a set of Product Owner Stories. We defined the value of a set of Product Owner Stories by the sum of the values of the corresponding and fully implemented User Stories.

Besides the structural change in Scrum, when introducing Product Owner Stories, we identified the Product Owner overload as an obstacle to achieve our goal.

As a next research step we want to analyse different provisions to reduce the workload of the Product Owner in order to create enough open space to identify synergies between User Stories. We also have to investigate the prerequisites for a beneficial consolidation of User Stories with Product Owner Stories. Furthermore we have to investigate the implications for the iteration planning and its value maximization.

\section{REFERENCES}

[1] S. Chen, B. Mulgrew, and P. M. Grant, "A clustering technique for digital communications channel equalization using radial basis function networks," IEEE Trans. on Neural Networks, vol. 4, pp. 570-578, July 1993.

[2] W. Neubauer and B. Rudow, Trends in the Automotive Industry, München: Oldenbourg, 2012, ch. 5.

[3] K. Petersen, "Implementing lean and agile software development in industry," Ph.D. dissertation, Blekinge Institute of Technology, 2010.

[4] K. Wnuk, B. Regnell, and B. Berenbach, "Scaling up requirements engineering-exploring the challenges of increasing size and complexity in market-driven software development," Requirements Engineering: Foundation for Software Quality, Springer, 2011, pp. 54-59.

[5] Z. Racheva, M. Daneva, and K. Sikkel, "Value creation by agile projects: Methodology or mystery?" Product-Focused Software Process Improvement, Berlin, Heidelberg: Springer Berlin Heidelberg, 2009, pp. 141-155.

[6] P. Daut, "Alternative to the role of product owner or how do we remain agile?: The scaling of agility in large organizations," Business Technology, vol. 4, pp. 6-12, 2013.

[7] P. Bitzer, H.-C. Heidecke, and J. M. Leimeister, "Towards an approach for the systematic identification of IT-value," Betriebliche Informations Systeme in der Automobilproduktion, Oldenbourg, 2014, pp. 261-286.

[8] T. Saaty, The Analytic Hierarchy Process: Planning, Priority Setting, Resource Allocation, PA: RWS Publications, 1990, ch. 4.

[9] R. Pichler, Agile Product Management with Scrum: Creating Products That Costumers Love, Addision-Wesley Professional, 2010, ch. 3, pp. 53-71.

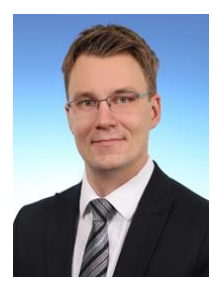

Fabian Sobiech is a $\mathrm{PhD}$ candidate at the Clausthal University of Technology. He is also a member of the $\mathrm{PhD}$ program at Volkswagen in Wolfsburg. His main research interest is in the area of agile requirements engineering for larger software projects. He is especially interested in intern software projects within the automotive industry.

Until 2010 he made his bachelor in IT systems engineering at the Hasso Plattner Institut in Potsdam. Afterwards he made his M.Sc. in computer science at the Leibniz University Hannover. 


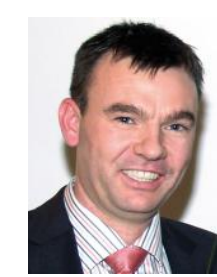

Andreas Rausch is the head of the chair for software systems engineering at the Clausthal University of Technology. Until early 2007 he was the head of the chair for software architecture at the University of Kaiserslautern.

In 2001 he obtained his doctorate at the University of Munich under Prof. Dr. Manfred Broy. His research in the field of software engineering focuses on software architecture, model-based software engineering and process models, with more than 70 publications worldwide.

Prof. Dr. Andreas Rausch is the project leader for the development of the new V-model XT, the standard system development process model for IT systems of the Federal Republic of Germany. In addition to his research activities he participated in various commercial software projects developing large distributed systems. He is one of the four founders and shareholders of the software and consulting company $4 \mathrm{Soft} \mathrm{GmbH}$, Munich.

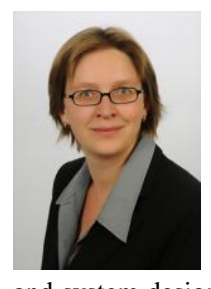

Beate Eilermann is the head of lean administration at Volkswagen AG, Wolfsburg. She was born in 1978, academic degree of business administration, master of human factors and $\mathrm{PhD}$ in psychology. Between 2011 and 2014, she is the head of management systems and enterprise resource planning at Volkswagen Group. Since 2011 she was teaching assignment at the Ostfalia University of applied science focus usability engineering and system design. From 2006 to 2008, she was a teaching assistant at the Department of Human Factors Engineering and Ergonomics at the Technical University of Berlin. She has several years of professional experience in automotive industry and the finance sector in Germany and Luxembourg Her research focuses are in user experience, usability, business information systems, lean office, work organization and organizational psychology. 